\section{Should Residency Projects Involve More than One Resident?}

\section{THE "PRO" SIDE}

The accreditation standards of the Canadian Hospital Pharmacy Residency Board (CHPRB) require that pharmacy residents conduct and complete a project related to pharmacy practice. ${ }^{1}$ Residents must be involved in the development of the project and in the collection, analysis, and interpretation of the data. In addition, the project report must be prepared in a format suitable for publication in a peer-reviewed journal and presented as a poster by the residents. ${ }^{1}$ Residency projects are an important part of residents' training, as they offer a unique opportunity to learn and apply the basics of research methodology, demonstrate project management skills, and contribute to the biomedical literature. Gaining such research skills is also valued by practising pharmacists. In a recent survey of Canadian hospital pharmacists practising in critical care, $97.2 \%$ of respondents believed that involvement of critical care pharmacists in research was desirable, and many (80.4\%) expressed interest in becoming more involved in research. ${ }^{2}$

The CHPRB accreditation standards offer no recommendation related to whether the residency project must be carried out individually or whether it can be conducted by a team of residents. For many years, residents in the Master's in Advanced Pharmacotherapy program at the Université de Montréal have carried out their residency projects in teams ranging from 2 to 5 people, usually within the same affiliated health centre; in fact, for more than a decade, there have been no projects involving just a single resident. This situation contrasts sharply with other Canadian residency programs, which usually offer or require individual projects.

We recognize the many benefits of team-based residency projects. The first advantage is the potential to develop and apply a scientifically sound study design, including appropriate sample size. Inability to reach adequate sample size is one of the major limitations of residency projects conducted by individual residents. Increasing the duration of data collection by having consecutive residents enroll patients allows for a sample size of sufficient magnitude for appropriate statistical power and precision, which are essential conditions for inference of appropriate conclusions. In fact, many institutional review boards consider it unethical to conduct a study with insufficient statistical power. Having different residents conduct research projects over several months also allows implementation of more complex research designs, such as prospective cohort studies and clinical trials. Finally, such projects have a greater chance of being published and are therefore more likely to contribute to the advancement of pharmacy research, thus increasing the satisfaction not only of the residents but also of the preceptors, coauthors, residency programs, pharmacy departments, and institutions. In a recent study evaluating publication rates of Canadian pharmacy practice residents' projects from 1999 to 2009, the overall publication rate (as an abstract or a manuscript) was $32.2 \% .^{3}$ Over the last 3 years of the study (2007, 2008, and 2009), the publication rate as a manuscript was $22.4 \%, 23.2 \%$ and $12.6 \%$, respectively. In contrast, at the Université de Montréal, $46.8 \%$ of pharmacy residency projects were presented as abstracts over 11 years between 1997 and 2007. ${ }^{4}$ During the same period, $22.6 \%$ of the projects were published, the majority (82\%) in indexed journals. ${ }^{4}$ In a PubMed search of residency projects conducted in 2007, 2008, and 2009 , we identified $25 \%, 33 \%$ and $35 \%$ of the residency projects, respectively, as having been published.

The second advantage of a team-based residency project is that it emulates real-life situations. Contemporary research typically involves collaboration with a variety of professionals of similar or different backgrounds. Exposing pharmacy residents to work with individuals of different opinions, backgrounds, strengths, and weaknesses is important in developing professional competencies. In conducting a collaborative project, all of the residents are involved in development of the research protocol, data collection, data analysis, presentation of results as an abstract, and writing of the report as a manuscript for publication. However, the contribution of individual residents with regard to data collection and analysis may vary, depending on timing of their research rotations in relation to the overall project. ${ }^{5}$ Developing strategies to ensure rigorous and uniform data collection when many individuals are involved is another valuable part of research training, as timely and effective communication and interpersonal skills are required. In addition, ensuring equivalent contributions from all members of the team can be a challenge. However, this is also true of real-life pharmacy practice and research endeavours. Adapting project evaluation to incorporate individual evaluations, according to each resident's involvement, as well as peer evaluation (i.e., residents evaluating each other), is a strategy that can be used to overcome this limitation.

Pharmacy residency programs can realize potential efficiencies through team-based pharmacy residency projects. Concentrating efforts on one larger project, rather than many smaller 
projects, can be an incentive for preceptors to become involved. When residents are conducting large-scale research projects, they often contribute substantially to the research program of their faculty or clinical director and also contribute to the research component of the pharmacy department's mission. Many of these projects are already funded through the director's research program, or it may be possible to obtain appropriate funding from the department. Although supervising pharmacy residency projects can be very time consuming, faculty members are now considering the benefits of taking on this task. Recent examples include the ProFil (Programme de formation et de liaison en néphrologie) research program to evaluate the impact of a training and communication network program in nephrology, to facilitate the detection and management of drug-related problems by community pharmacists. In total, 6 teams of residents over multiple years have participated in various projects within this program, which have led to multiple publications..$^{6-8}$ Other successful projects have evaluated management and outcomes of respiratory disease $e^{-11}$ and thromboprophylaxis. ${ }^{12-14}$

In conclusion, pharmacy residency projects involving more than one resident meet CHPRB requirements and are beneficial to all parties involved. Pharmacy residents acquire excellent research training and other professional competencies, the institution (hospital pharmacy department, institutional research centre, or faculty of pharmacy) receives significant recognition for its research programs, and hospital pharmacy practice in general benefits from the research advancements achieved.

\section{References}

1. Canadian Hospital Pharmacy Residency Board. Accreditation standards, January 2010. Ottawa (ON): Canadian Society of Hospital Pharmacists; 2009 [cited 2013 Oct 24]. Available from: www.cshp.ca/programs/ residencyTraining/CHPRB_Standards_2010_-_FINAL.pdf

2. Perreault MM, Thiboutot Z, Burry LD, Rose L, Kanji S, LeBlanc JM, et al. Canadian survey of critical care pharmacists' views and involvement in clinical research. Ann Pharmacother. 2012;46(9):1167-73.

3. Hung M, Duffett M. Canadian pharmacy practice residents' projects: publication rates and study characteristics. Can J Hosp Pharm. 2013;66(2):86-95.

4. Perreault MM, Turgeon N, Williamson DR, Lalonde L. Ten years of residency projects: a review [abstract]. Am J Pharm Educ. 2008;72:29.

5. Egan G, Seaton A. Completing a residency project involving 2 residents [letter]. Can J Hosp Pharm. 2012;65(4):323-4.

6. Legris MÈ, Séguin NC, Desforges K, Sauvé P, Lord A, Bell R, et al. Pharmacist Web-based training program on medication use in chronic kidney disease patients: impact on knowledge, skills, and satisfaction. $J$ Contin Educ Health Prof. 2011;31(3):140-50.

7. Desrochers JF, Lemieux JP, Morin-Bélanger C, Paradis FS, Lord A, Bell R, et al. Development and validation of the PAIR (Pharmacotherapy Assessment in Chronic Renal Disease) criteria to assess medication safety and use issues in patients with CKD. Am J Kidney Dis. 2011;58(4):527-35.

8. Guay M, Ricard S, Letendre S, Clément V, Lord A, Bell R, et al. Connaissances et compétences des pharmaciens communautaires et qualité de la pharmacothérapie chez les patients atteints d'insuffisance rénale chronique. Pharmactuel. In press.

9. Thuot M, Coursol MA, Nguyen S, Lacasse-Guay V, Beauchesne MF, Fillion A, et al. Impact of obesity on perinatal outcomes among asthmatic women. Can Respir J. 2013;20(5):345-50.
10. Beauchesne MF, Bercier D, Julien-Baker F, Lalonde L, Boileau R, Blais L. Community pharmacy-based medication assessment program for asthma and chronic obstructive pulmonary disease. Can Pharm J. 2012;145(2):70-1.

11. René-Henri N, Khamla Y, Nadaira N, Ouellet C, Blais L, Lalonde L, et al. Community pharmacists' interventions in asthma care: a descriptive study. Ann Pharmacother. 2009;43(1):104-11.

12. Vincent PD, Albert M, Champagne MC, Zikos T, Boulanger I, Blais L, et al. Factors influencing enoxaparin anti-Xa activity in surgical critically ill patients. J Crit Care. 2011;26(4):347-51.

13. Bernier MC, Desjardins K, Filiatrault J, Sauriol MA, Martineau J, Gilbert E, et al. Implementation and evaluation of a pharmacy-led thromboprophylaxis campaign in a community hospital. $J$ Thromb Thrombolysis. 2011;32(4): 431-8.

14. Bazinet A, Almanric K, Brunet C, Turcotte I, Martineau J, Caron S, et al. Dosage of enoxaparin among obese and renal impairment patients. Thromb Res. 2005;116(1):41-50.

David R Williamson, BPharm, MSC, BCPS

Associate Clinical Professor

Lyne Lalonde, BPharm, PhD

Full Professor

Faculty of Pharmacy

Université de Montréal

Montréal, Quebec

David Williamson is also a Critical Care Pharmacist in the Pharmacy Department of Hôpital du Sacré-Coeur de Montréal, Montréal, Quebec. Lyne Lalonde is also a Researcher with the Centre de recherche du Centre hospitalier universitaire de Montréal, Montréal, Quebec.

Competing interests: Lyne Lalonde has received grant funding for projects mentioned in this article from the Canadian Institutes of Health Research, Amgen, and LEO Pharma. None declared by Mr Williamson.

\section{THE "CON" SIDE}

The residency program offered to pharmacists wishing to practise in a health care institution has several goals; in addition to the clinical objectives, each resident is expected to develop and conduct a research project on a scientific, clinical, or administrative aspect of pharmacy practice within a health care institution. ${ }^{1,2}$

In the Master's in Advanced Pharmacotherapy program of Université Laval's Faculty of Pharmacy, most residency projects are conducted by an individual resident. Why? Our project partners are pharmacists from health care facilities that offer the clinical component of the residency program. As Barletta ${ }^{3}$ stated, proposing the "right" research project from the start is crucial. Thus, the type and scope of the project should meet the needs of our experiential settings. Our experience has shown that research projects on practice evaluation, conformity with a protocol or guideline, development of a tool, drug-use evaluation (including management of an adverse effect), or pharmacokinetics, as well as studies to answer clinical questions, are examples of projects that not only meet our partners' needs but also can be undertaken by an individual resident. ${ }^{49}$

According to Barletta, ${ }^{3}$ projects that cannot be completed in the course of a 1-year residency should be discouraged. Although 
prospective, randomized controlled trials constitute the most rigorous method for answering a research question, they require several years and are therefore unsuitable because of time constraints. ${ }^{3}$ Furthermore, completing a research project should not interfere with the acquisition of clinical skills. Indeed, the residency program is demanding and the time allowed for the project is limited. ${ }^{2}$ Barletta supports the idea of developing projects that are not expected to last beyond 1 year, so that residents can be exposed to all stages of the research project. ${ }^{3} \mathrm{~A}$ resident conducting a project alone gains the knowledge and skills specific to each stage of the project (defining the topic, formulating operational objectives, planning activities according to personal schedule, obtaining required authorizations, developing data collection tools, collecting and analyzing the data, interpreting the results, and preparing oral and written presentations). The resident will thus be able to develop critical and logical thinking that can be used in planning future projects, to demonstrate project management skills, and to share his or her knowledge.

Projects carried out by individual residents are definitely beneficial for supervisors. The assignment of tasks for the project is much simpler. Thus, there is no question about the relative contribution of each resident to a project. Another benefit is the absence of variability in data collection, which typically arises when more than one resident is involved. These problems represent limitations to the results of a project carried out by several researchers. ${ }^{10}$

Moreover, projects carried out by individual residents may prevent certain communication problems. Egan and Seaton reported that communication can be problematic when opinions, communication styles, or visions differ between residents. ${ }^{10}$ Additionally, single-resident projects prevent personality conflicts between residents with different backgrounds or different ways of viewing collaboration. ${ }^{10}$ It is also necessary to mention the risk of a resident withdrawing from the program, which could jeopardize both the viability and feasibility of a multiresident project. The dissemination of project results is an important part of residency training. ${ }^{1,11}$ Hung and Duffett ${ }^{11}$ described the types of projects conducted within residency programs in Canada (excluding Quebec) and the publication rates by abstract and by article. According to their findings, published projects and the associated research topics are quite diverse and can usually be conducted by a single resident. ${ }^{11}$ Furthermore, for the majority of published projects (89.1\%), the work of each project was conducted at a single centre. Table 1 presents a few examples of single-resident projects within our faculty that have led to publications in recent years. ${ }^{4-9}$

Projects conducted by a single person do not allow for ambiguity about the choice of the first author of a publication. This recognition is not an insignificant factor since it represents a considerable benefit to the resident who wishes to pursue a career in research.

The project examples in Table 1, all carried out by individual residents, meet the requirements for residency projects of the Canadian Hospital Pharmacy Residency Board (CHPRB) ${ }^{1}$ :

- The resident shall be involved in project development, data collection, analysis and interpretation.

- The resident shall prepare a written report of the project in

\section{Table 1. Examples of Published Projects Conducted by a Single Pharmacy Resident (with Nonresident Collaborators)}

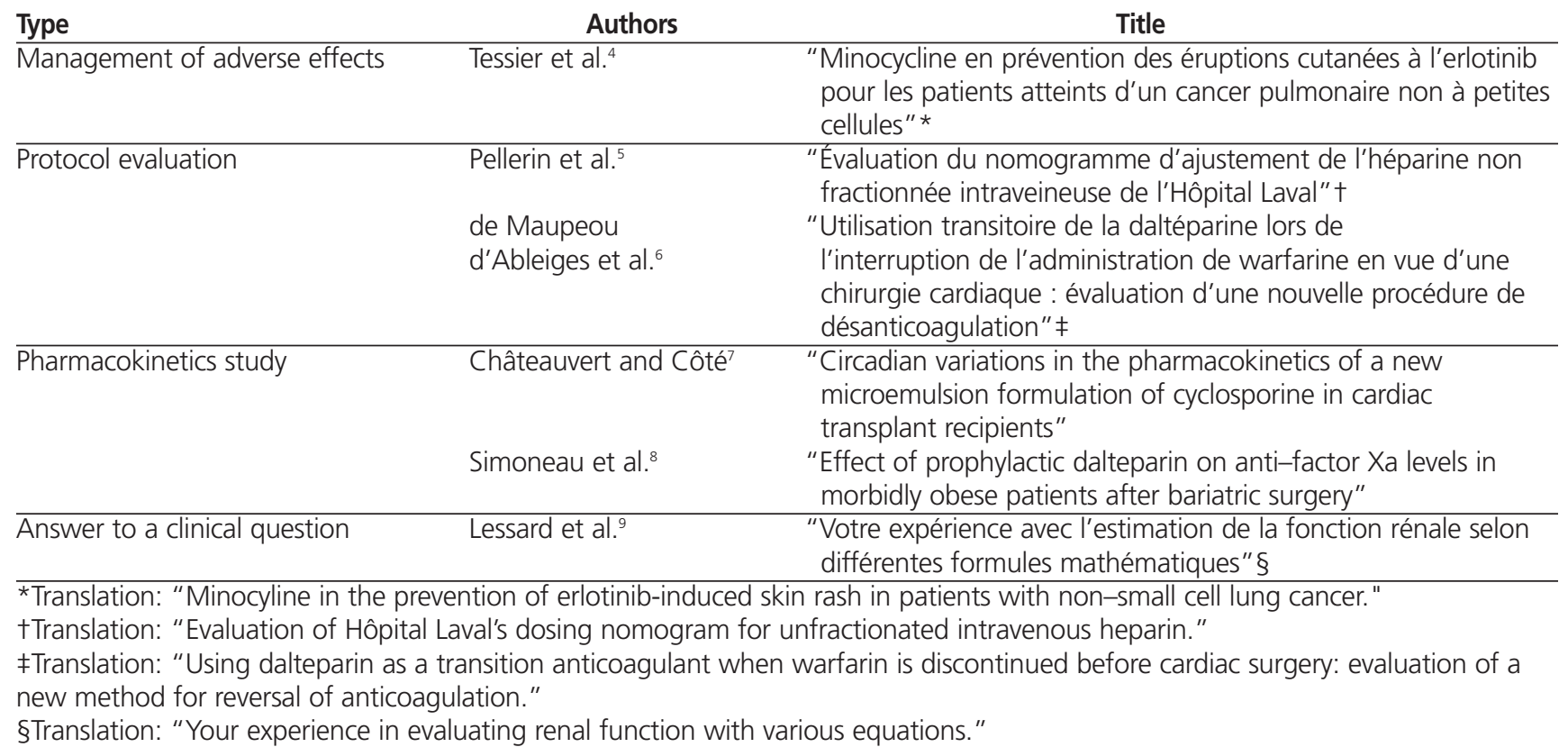


a format suitable for publication in a peer-reviewed journal.

- The resident shall present and defend the outcomes of the project.

Certain remote institutions have only one resident, which would also limit the opportunities for conducting team-based research projects. Two of our institutions are located more than $220 \mathrm{~km}$ from the city where our university hospitals are located. This geographic reality makes it that much harder to conduct team-based research projects.

Furthermore, the health care institutions welcoming our residents have very different patient populations and clinical expertise. For example, the Institut universitaire de cardiologie et de pneumologie de Québec (Quebec Heart and Lung Institute) is a highly specialized centre offering tertiary care in cardiology and pneumonology. ${ }^{12}$ The characteristics of the regional hospital of the Centre de santé et de services sociaux de RimouskiNeigette are very different, in that it provides mostly secondary services to its patient population. ${ }^{13}$ Our geographic distance from some institutions and their specialized missions are factors that promote research projects by individual residents.

In conclusion, residency projects completed by a single resident meet both the $\mathrm{CHPRB}$ requirements and the needs of our clinical partners, and they enable residents to be exposed to every stage of the research project. Once pharmacy residents have completed their projects, they will be able to address the issues of a research project meticulously and systematically. The types of projects and the research topics are diverse, and dissemination of results, including article publication, is strongly encouraged. The fact that some institutions have only one resident at a time, the variety of institutions' missions, and their geographic contexts all favour the conduct of projects by individual residents.

[Publisher's translation]

\section{References}

1. Canadian Hospital Pharmacy Residency Board. Accreditation standards, January 2010. Ottawa (ON): Canadian Society of Hospital Pharmacists; 2009 [cited 2013 Sep 16]. Available from: www.cshp.ca/programs/residencyTraining/ CHPRB_Standards_2010_-_FINAL.pdf

2. Maîtrise en pharmacothérapie avancée : description du programme de deuxième cycle. Quebec City (QC): Université Laval, Faculty of Pharmacy; 2013 [cited 2013 Oct 30]. Available from: www.pha.ulaval.ca/cms/site/pha/ pharmacie/ programmes-pharmacie/cycles-superieurs/maitrise-pharmacotherapieavancee
3. Barletta JF. Conducting a successful residency research project. Am J Pharm Educ. 2008;72(4):article 92 (7 pages).

4. Tessier JF, Gagnon PY, Côté J, Drolet B. Minocycline en prévention des éruptions cutanées à l'erlotinib pour les patients atteints d'un cancer pulmonaire non à petites cellules. Pharmactuel. 2013;46(2):78-86.

5. Pellerin J, Taillon I, Bélanger PM, Méthot J. Évaluation du nomogramme d'ajustement de l'héparine non fractionnée intraveineuse de l'Hôpital Laval. Pharmactuel. 2008;41(5):277-83.

6. de Maupeou d'Ableiges D, Daleau P, Voisine P, Châteauvert N. Utilisation transitoire de la daltéparine lors de l'interruption de l'administration de warfarine en vue d'une chirurgie cardiaque : évaluation d'une nouvelle procédure de désanticoagulation. Pharmactuel. 2008;41(4):208-17.

7. Châteauvert N, Côté H. Circadian variations in the pharmacokinetics of a new microemulsion formulation of cyclosporine in cardiac transplant recipients. Pharmacotherapy. 1998;18(2):364-70.

8. Simoneau MD, Vachon A, Picard F. Effect of prophylactic dalteparin on anti-factor Xa levels in morbidly obese patients after bariatric surgery. Obes Surg. 2010;20(4):487-91.

9. Lessard S, Blanchet M, Morin N, Lefebvre J. Votre expérience avec l'estimation de la fonction rénale selon différentes formules mathématiques. Pharmactuel. 2012;45(1):43-51.

10. Egan G, Seaton A. Completing a residency project involving 2 residents [letter]. Can J Hosp Pharm. 2012;65(4):323-4.

11. Hung M, Duffett M. Canadian pharmacy practice residents' projects: publication rates and study characteristics. Can J Hosp Pharm. 2013;66(2):86-95.

12. À propos de l'Institut : mission. Quebec City (QC) : Institut universitaire de cardiologie et de pneumologie de Québec; 2010 [cited 2013 Oct 30]. Available from: www.iucpq.qc.ca/apropos-mission.asp

13. Notre organisation : la mission. Rimouski (QC) : Centre de santé et de services sociaux de Rimouski-Neigette; (c) 2003-2013 [cited 2013 Oct 30]. Available from: www.chrr.qc.ca/organisation/mission/index.php

Julie Méthot, BPharm, PhD

Assistant Professor

Program Director, Master's in Advanced Pharmacotherapy

Chantale Simard, BPharm, PhD

Full Professor

Faculty of Pharmacy

Université Laval

Quebec City, Quebec

Julie Méthot is also a clinical pharmacist for the Institut universitaire de cardiologie et de pneumologie de Québec, Quebec City, Quebec. Chantale Simard is also a researcher for the research centre of the Institut universitaire de cardiologie et de pneumologie de Québec, Quebec City, Quebec.

Competing interests: Julie Méthot is the editor-in-chief of the journal Pharmactuel. None declared by Chantale Simard. 